\title{
Prenatal Diagnosis of Lysosomal Storage Disorders by Enzymes Study Using Chorionic Villus and Amniotic Fluid
}

\author{
Jayesh Sheth $\cdot$ Mehul Mistri $\cdot$ Frenny Sheth $\cdot$ \\ Chaitanya Datar $\cdot$ Koumudi Godbole . \\ Mahesh Kamate $\cdot$ Kamal Patil
}

Received: 17 April 2014/ Accepted: 20 May 2014/Published online: 3 July 2014

(C) Society of Fetal Medicine 2014

\begin{abstract}
The reported prevalence of lysosomal storage disorder (LSD) is 1:5,000-7,000 live births and with the limited availability of therapeutic option; prenatal diagnosis (PD) remains the only preventable cure for storage disorders. One hundred forty pregnancies having confirmed diagnosis of LSDs in index case were selected for enzymes study during PD from uncultured and/or cultured chorionic villus (CV/CCV) and cultured amniotic fluid (CAF) cells. In seven pregnancies, molecular analysis was additionally carried out where mutation was known in an index case. Of 140 pregnancies, $60(42.9 \%)$ were diagnosed as affected, $13(9.3 \%)$ had an intermediate enzyme activity and $67(47.8 \%)$ had normal enzyme activity. Results were confirmed in 83 cases whereas 57 cases were lost from the follow-up. In one case, enzyme $\beta$-galactose- 6 sulphate sulphatase specific for Morquio-A disorder [mucopolysaccharidosis-IVA
\end{abstract}

J. Sheth $(\varangle) \cdot$ M. Mistri $\cdot$ F. Sheth

Department of Biochemical and Molecular Genetics, FRIGE's Institute of Human Genetics, FRIGE House, Satellite,

Ahmadabad 380015, Gujarat, India

e-mail: jshethad1@gmail.com

\section{Datar}

Rare Genetic Disorder Clinic, Sahyadri Medical Genetics and Tissue Engineering Facility (SMGTEF), Pune, India

\section{K. Godbole}

Department of Genetics, Deenanath Mangeshkar Hospital \& Research Center, Erandawane, Pune, India

\section{Kamate}

Department of Pediatric Neurology and Child Development Center, KLES PK Hospital, Belgaum, India

K. Patil

Department of Obstetrics \& Gynecology, KLES PK Hospital, Belgaum, India
(MPS-IVA)] had shown $30 \%$ reduced activity in CV cells and the case was diagnosed as carrier for MPS-IVA while it delivered an affected child. Further molecular analysis in seven cases that included six with Tay-Sachs and one with Gaucher disease, confirmed the results obtained by enzymatic study during PD. PD of LSDs can be carried out by enzymes study from CV/CCV and CAF with an accuracy of molecular method. However, in cases of MPS and mucolipidosis, Amniotic fluid (AF) is preferred over CV/CCV. In addition, special care is needed while interpreting enzyme results encompassing carrier status and they need to be further evaluated by molecular studies.

Keywords Lysosomal storage disorders - Prenatal diagnosis · Enzyme assays · Chorionic villus sampling · Amniotic fluid studies

\section{Introduction}

Prenatal diagnosis (PD) is one of the important approaches for the prevention of lysosomal storage disorders (LSDs) where treatment options are either beyond the financial reach of the family or are not available. Various methods have been employed in the PD of LSDs that include morphological study of uncultured chorionic villus (CV) cells for vacuoles [1], enzyme study from CV cells, cultured chorionic villus (CCV) and/or cultured amniotic fluid (CAF) cells [2], electrophoresis of AF for excretion pattern of various mucopolysaccharides (MPSs) [3], electroscopic ionization tandem mass spectrometry [4] and mutation analysis using DNA from $\mathrm{CV}$ and $\mathrm{AF}$ [5].

Molecular studies provide precise PD of the LSDs. However, mutation detection in an affected child is the 
prerequisite [6], which is not available in most of the cases with storage disorders in developing countries due to the cost and absence of common mutation screening. Hence, lysosomal enzyme studies are important for PD by most of the centers where the diagnosis in the index case has been confirmed $[1,2,7]$. Very few reports are available from India where LSDs were detected during PD using lysosomal enzymes [8-10]. Nonetheless, considering the reported prevalence of the disease [11], the significant burden of various LSDs reported by Sheth et al. [12] from India and its limited therapeutic options, PD remains the only preventable measure for LSDs. The present study was carried out to evaluate the sensitivity and specificity of lysosomal enzyme assays for the PD of LSDs from $\mathrm{CV} / \mathrm{CCV}$ and CAF cells.

\section{Materials and Methods}

A prospective study of 140 pregnancies from 2006 to 2013 was carried out from CV/CCV and/or CAF cells for the PD of LSDs by lysosomal enzyme where the diagnosis in the index case was confirmed. A written informed consent was obtained from the patients as per the Prenatal Diagnosis Act and counseling was provided to each family.

Prenatal sampling was done depending upon the stage of pregnancy, fetal position and maternal health. CV sampling and/or amniocentesis was carried out between 10-13 and 15-18 weeks of gestation, respectively as per the standard procedure. Enzyme analysis was carried out from CV cells in 16 cases, $\mathrm{CV}$ and $\mathrm{CCV}$ both in 19 cases, $\mathrm{CCV}$ alone in 19 whereas CAF cells were analyzed in 86 cases by the method described below. All prenatal diagnostic samples were simultaneously processed with sample matched positive and negative controls for the required enzymes.

The CV samples were collected in a sterile collection vial containing a medium to minimum quantity of 10-15 mg. After checking for maternal cell contamination, they were thoroughly washed with sterile phosphate buffered saline (PBS) followed by distilled water. CV samples were homogenized on ice. After repeated freezing and thawing, supernatant was used for direct enzyme study with protein concentration between 2 and $10 \mathrm{mg} / \mathrm{mL}$ [1].

After thorough examination and washing with PBS, CV samples were chopped and cultured in growth medium under $5 \% \mathrm{CO}_{2}$ as per standard protocol $[1,2]$. Once cell confluence was obtained, which usually takes 2 weeks time, they were harvested carefully and protein activity was determined. Final concentration of protein was kept $2-10 \mathrm{mg} / \mathrm{mL}$ and it was used for enzyme study.

About $15-20 \mathrm{~mL}$ of fluid was collected without maternal blood contamination. Following centrifugation, cells were cultured in two different growth mediums. After cell confluence was attained, the grown fibroblasts were processed for different lysosomal enzyme study after protein estimation $[1,2]$.

Enzyme activity was carried out using the synthetic substrate 4-methylumbelliferrone-fluorogenic substrate and $p$-nitrocatechol sulfate-spectrophotometric substrate [13]. As shown in Table 1, the present study included 140 patients for various LSDs depending upon the diagnosis in affected sibs. The enzyme activity was expressed as $\mathrm{nmol} / \mathrm{h} / \mathrm{mg}$ of protein except $\mathrm{nmol} / 4 \mathrm{~h} / \mathrm{mg}$ of protein for $\alpha$-iduronate sulfatase and $\mathrm{nmol} / 17 \mathrm{~h} / \mathrm{mg}$ of protein for $\beta$-galactose-6-sulphate-sulfatase, heparan sulphamidase and $\beta$-galactocerebrosidase.

Genomic DNA was isolated from $\mathrm{CV} / \mathrm{CCV}$ and $\mathrm{CAF}$ cells using salting out method [14]. Molecular analysis was carried out in seven pregnancies that included six with TaySachs disease (HEXA gene) and one with Gaucher disease (GBA gene) [15-17] where mutation in index case was known.

\section{Results}

Table 2 demonstrates the normal range of lysosomal enzymes expressed in various prenatal tissues where normal child was delivered and a follow-up study was carried out till 1 year of age confirming the normal status. Test results were compared using them as a reference range.

The preponderance of the diagnosis in the index case was observed for glycolipid or sphingolipid degradation (46\%) followed by glycosaminoglycans (GAGs) degradation (mucopolysaccharidoses $27.6 \%$ ), sulfatide degradation $(13.5 \%)$, glycogen degradation (Pompe disease $5.6 \%$ ), protein degradation (NCL-II $1.4 \%$ ), and defect in lysosomal trafficking proteins [mucolipidosis-II/III (ML-II/ III) $5 \%$ ]. Of 140 prenatal cases studied, 60 (42.8\%) pregnancies were found to be affected with various LSDs with enzyme activity of $0-10 \%$. Thirteen $(9.2 \%)$ pregnancies have shown the carrier status with approximate intermediate enzyme activity expression of $(\sim 50 \%$ of mean), while $67(47.8 \%)$ pregnancies have shown normal enzyme activity in Table 2.

From the affected fetuses, 5 (3.5\%) were affected with Niemann-Pick disease-A/B (NPD-A/B), 6 (4.3\%) with GM1 gangliosidosis, 3 (2.1\%) with Tay-Sachs disease, 2 $(1.4 \%)$ with Sandhoff disease, $1(0.7 \%)$ with Gaucher disease, 11 (7.8\%) with Hurler disease (MPS-I), 3 (2.1\%) with Hunter disease (MPS-II), $1(0.7 \%)$ with Sanfilippo type-A (MPS-IIIA), 2 (1.4\%) with Sanfilippo type-B (MPS-IIIB), 4 (2.8\%) with Morquio-A (MPS-IVA), 2 $(1.4 \%)$ with Maroteaux-Lamy syndrome (MPS-VI), 2 $(1.4 \%)$ with metachromatic leucodystrophy (MLD), 7 (5.0 \%) with Krabbe disease, 5 (3.5\%) with Pompe 


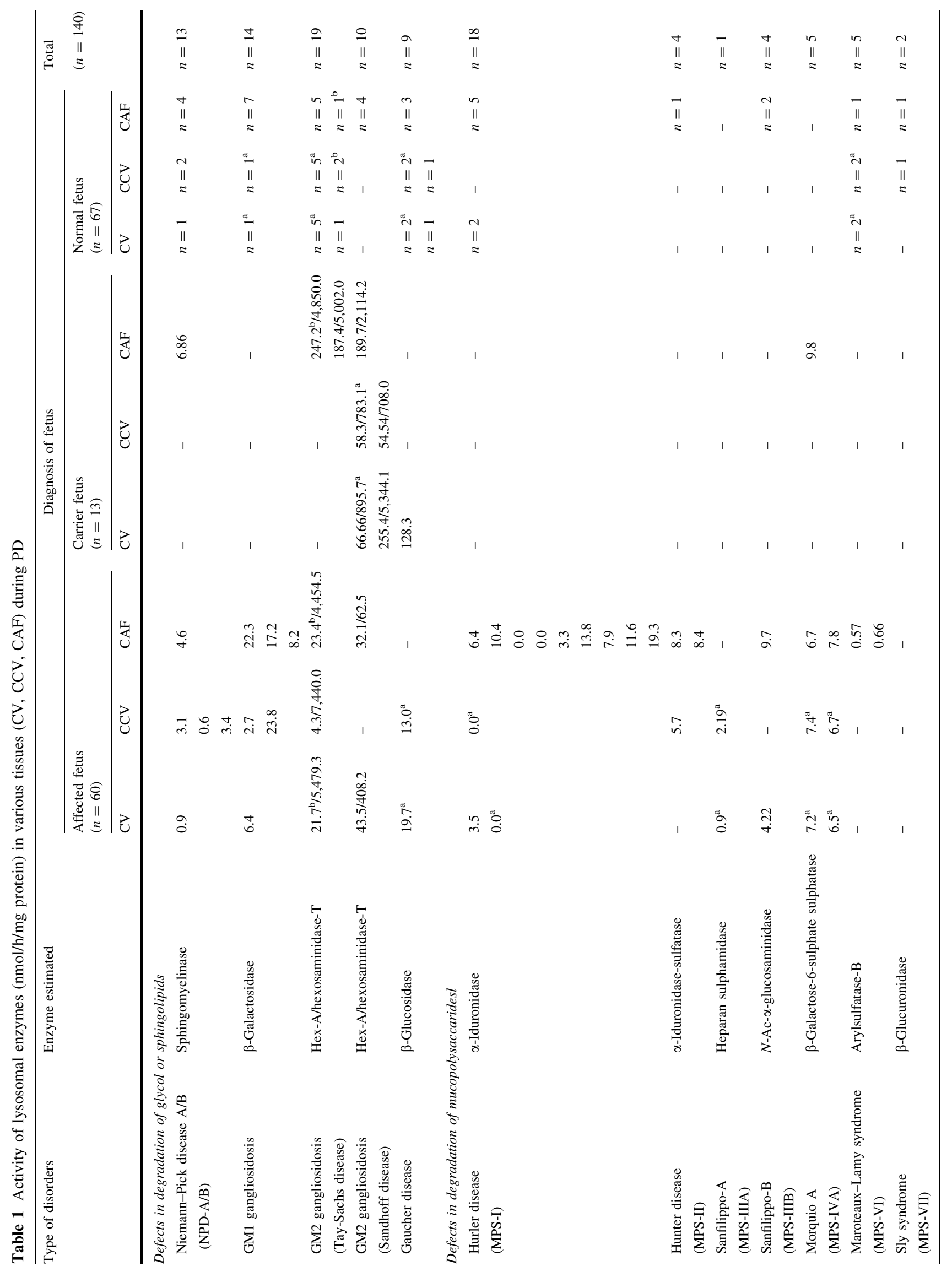




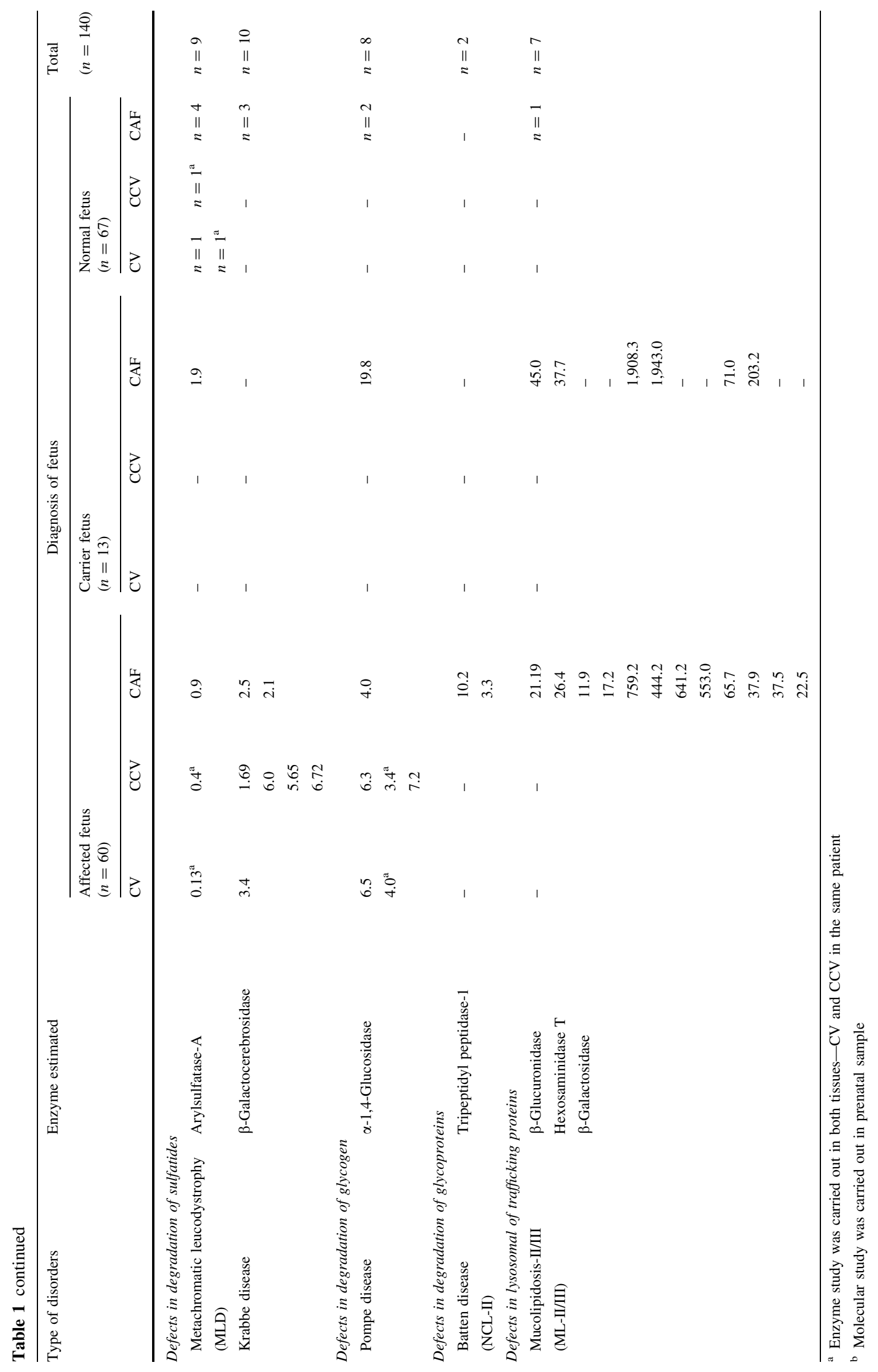


Table 2 Normal values of lysosomal enzymes in various biological tissues

\begin{tabular}{|c|c|c|c|}
\hline \multirow[t]{2}{*}{ Deficient enzymes (units) } & \multicolumn{3}{|c|}{ Normal ranges } \\
\hline & $\begin{array}{l}\text { Uncultured CV } \\
(\mathrm{CV})^{\mathrm{a}}\end{array}$ & $\begin{array}{l}\text { Cultured CV } \\
(\mathrm{CCV})^{\mathrm{a}}\end{array}$ & $\begin{array}{l}\text { Cultured amniotic } \\
\text { fluid cells }(\mathrm{CAF})^{\mathrm{a}}\end{array}$ \\
\hline Sphingomyelinase (nmol/h/mg protein) & $7.95-13.61(8)$ & $13.3-18.8(4)$ & $17.0-69.4(8)$ \\
\hline Hexosaminidase-A (nmol/h/mg protein) & $298-929.0(10)$ & $271-1,621(8)$ & $271-2,213.2(9)$ \\
\hline Hexosaminidase- $\mathrm{T}$ (nmol/h/mg protein) & $1,000-1,728(13)$ & $4,507-15,473.2(15)$ & $4,487.0-16,286.2(25)$ \\
\hline$\beta$-Galactosidase (nmol/h/mg protein) & $131.28-501.0(6)$ & $150-644(25)$ & $296-1,195(30)$ \\
\hline$\beta$-Glucosidase (nmol/h/mg protein) & 90-198 (9) & $115-409(18)$ & $118-584.8(30)$ \\
\hline$\alpha$-Iduronidase (nmol/h/mg protein) & $12.0-32.5(11)$ & $19.27-93.4(10)$ & $85.5-156.3(14)$ \\
\hline$\alpha$-Iduronidase-sulfatase (nmol/4 h/mg protein) & $28.1-48.0(3.0)$ & $218.7-372.0(4)$ & $63.1-261.1(17)$ \\
\hline Heparan sulphamidase (nmol/17 h/mg protein) & $2.5-8.0(3)$ & $10.2-25.3(3)$ & ND \\
\hline$N$-Ac- $\alpha$-glucosaminidase (nmol/h/mg protein) & ND & ND & $21-73.3(6)$ \\
\hline$\beta$-Galactose-6-sulphate sulphatase (nmol/17 h/mg protein) & $19.4-22.5(3)$ & $20.8-38.9(3)$ & $16.8-25.1(5)$ \\
\hline Arylsulfatase-B (nmol/h/mg protein) & $1.3-3.8(3)$ & $2.6-4.75(4)$ & $3.5-8.1(6)$ \\
\hline$\beta$-Glucuronidase (nmol/h/mg protein) & $91.04-135.13(8)$ & $26.5-149.6(11)$ & $50.07-197.1(13)$ \\
\hline Arylsulfatase-A (nmol/h/mg protein) & $1.08-6.0(4)$ & $3.5-8.0(5)$ & $3.0-6.0(9)$ \\
\hline$\beta$-Galactocerebrosidase (nmol/17 h/mg protein) & $20.8-56.8(4)$ & 21.9-99.5 (4) & 20.1-74.93 (10) \\
\hline$\alpha$-1,4-Glucosidase (nmol/h/mg protein) & $92.2-116.9(3)$ & $30.0-90.8(8)$ & $28.6-75.0(10)$ \\
\hline Tripeptidyl peptidase-1 (nmol/h/mg protein) & ND & $59.1-78.8(3)$ & 27.3-306 (10) \\
\hline
\end{tabular}

Number of cases investigated under each category is shown in parenthesis

${ }^{\text {a }}$ Number of cases studied from CCV includes CV cells while those with CAF have not been studied from CV or CCV

disease, $2(1.4 \%)$ with Batten disease (NCL-II) and 4 $(2.8 \%)$ with ML-II/III. Intermediate enzyme activity ( $\sim 50 \%$ of mean) was detected in $13(9.2 \%)$ pregnancies that includes $4(2.8 \%)$ fetuses with Sandhoff disease, 2 $(1.4 \%)$ with Tay-Sachs disease, $2(1.4 \%)$ with ML-II/III, each 1 ( $0.7 \%$ for each) with Gaucher, MLD, NPD-A/B and Pompe disease. Except one case of MPS-IVA which was found to be a carrier ( $\sim 30 \%$ enzyme activity) during PD and was found to be affected postnatally.

Molecular analysis was carried out in seven pregnancies followed by enzyme study with known mutation in the index case. This was carried out for Tay-Sachs disease in six pregnancies, of which two were affected. Homozygous mutation for $4 \mathrm{bp}$ insertion at c.1277_1278insTATC (p.Y427IfsX5) and c.320G $>$ A (p.E114K) one each was detected in enzymatically confirmed affected fetus same as seen in the index case. Enzymatically proven carrier subject $(n=1)$ showed only one copy of mutation c.964G $>$ A (p.D322N). In remaining three case subjects, absence of mutation [c.964G $>$ A (p.D322N), c.964G $>$ A (p.D322N)/ c.1277_1278insTATC (p.Y427IfsX5) and c.1454G $>$ A (p.W485X)] in HEXA gene further supports the enzymatic results (Fig. 1). Mutation analysis of Gaucher disease carried out in a case during PD showed carrier status for c.1448T >C (p.L444P or p.L483P) mutation in GBA gene same as carrier (Fig. 2).

\section{Discussion}

The present study demonstrates the utility of fetal tissue in the PD of various lysosomal disorders. Various combinations such as $\mathrm{CV}, \mathrm{CCV}$ and $\mathrm{CAF}$ were used in the study. Total 140 cases were investigated and $60(42.9 \%)$ were found to be affected, $13(9.2 \%)$ were carrier and 67 (47.8\%) were normal. In 19 cases, CCV were processed in addition to $\mathrm{CV}$ and comparable results were observed for affected, carrier and normal in all the case subjects except one. This further confirms the previous report about fetal tissue that can be utilized for the diagnosis of various LSDs using lysosomal enzyme during PD. [1, 2, 18].

None of the cases has shown any difference in enzyme activity in CV or CCV cells in any of the 19 subjects which further suggests that direct $\mathrm{CV}$ cells can be used reliably for the rapid PD of LSDs. However low activity of $\alpha$-iduronidase has been reported in uncultured CV cells as compared to CCV cells [19] and doubts have been expressed for the reliability of using only uncultured $\mathrm{CV}$ cells for Hurler disease. Although Young [20] has observed CV cells to be highly reliable in 24 pregnancies affected by Hurler disease, caution must be taken in cases where high residual activity is detected in CV. This needs further confirmation either by $\mathrm{CCV}$ cells or CAF cells as detected in one of our case. Initially $\mathrm{CV}$ and $\mathrm{CCV}$ both were processed for MPS-IVA 


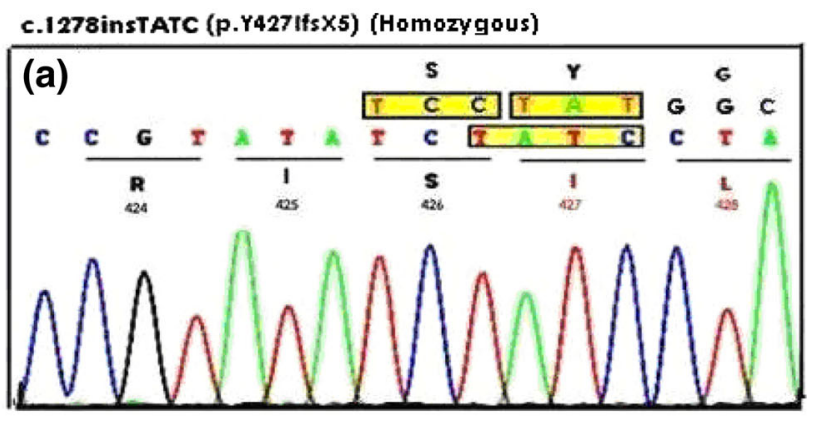

c.320 G>A (P.E114K) (Homozygous)

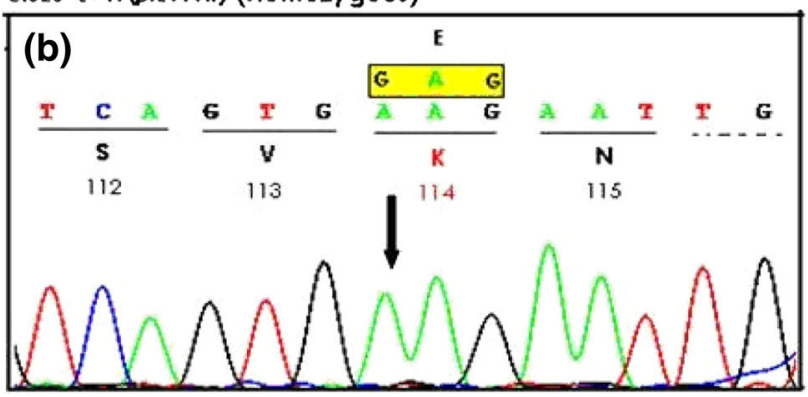

C.964 G>A (p.D322N) (Heterozygous)

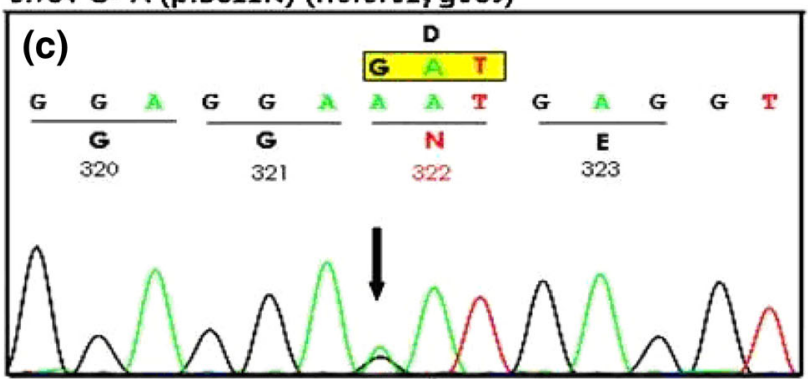

Fig. 1 a-c Chromatogram of HEXA gene mutations. a c.1277_1278insTATC (p.Y47IfsX5, homozygous), b c.320G $>$ A (p.E114K, homozygous), and c c.964G $>$ A (p.D322N, heterozygous)

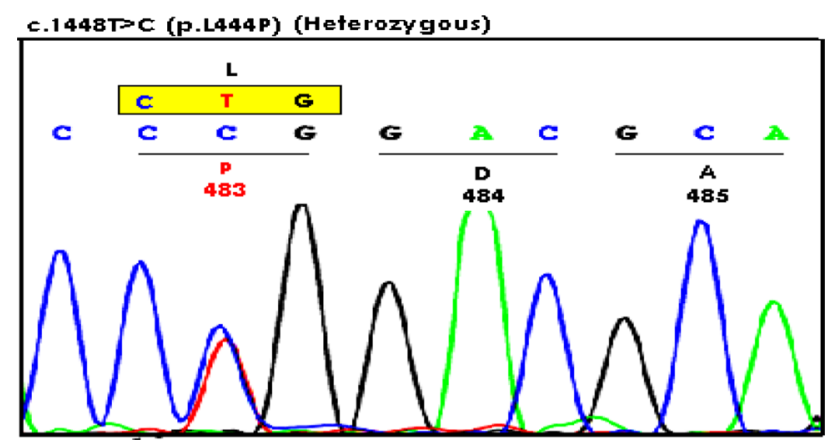

Fig. 2 Chromatogram of c.1448 (p.L444P) mutation in $G B A$ gene (heterozygous)

where $30 \%$ enzyme activity was detected and was considered as carrier but on follow-up after delivery, it was found to be affected. This indicates that in MPS cases, where residual activity of enzyme in $\mathrm{CV}$ cells is high, AF study by GAG excretion pattern in combination with CAF cells could be the preferred choice as suggested by Lake et al. [1]. They could make PD based on AF-GAG analysis followed by enzyme study from CAF cells. Moreover, Zhang et al. [21] also could make the prenatal confirmative diagnosis of MPS-III (Sanfilippo A/B) based on AF-GAG study.

Intermediate activity of hexosaminidase-A (Hex-A) with normal total-hexosaminidase (Hex-T) activity was detected in two pregnancies suggesting carrier status for Tay-Sachs disease (GM2 gangliosidosis). Due to overlapping activity of Hex-A in B1 variant of GM2 gangliosidosis, the authors used synthetic substrate (4-methylumbelliferyl $\beta$ - $N$-acetyl glucosamine-6-sulphate) instead of heat inactivation, where Hex-A remains low in B1 variant [1]. This could perhaps minimize the isoenzyme interference in GM2 gangliosidosis which is commonly observed in these cases and those with MLD and Maroteaux-Lamy syndrome (MPS-VI) [22].

Multiple enzyme deficiency is the gold standard for the diagnosis of ML-II/III. AF supernatant can be used as an initial screening test to measure enzyme activity which gets elevated in an affected pregnancy with ML-II/III disease [23]. None of the cases was studied for direct enzyme study from AF. In the present study, out of seven cases suspected with ML-II/III, four were confirmed to have low activity of multiple enzymes in CAF especially $\beta$-glucuronidase, $\beta$-Hex-T and $\beta$-galactosidase while in remaining three cases two were shown intermediate enzymes activities and one was normal which was confirmed postnatally. However Besley et al., carried out AF-supernatant study from a fetus affected with I-cell diseases (ML-II) for arylsulfataseA, $\beta$-Hex-T and $\beta$-glucuronidase, but in another pregnancy from a different family the AF enzyme activities were not raised, though the activities in CAF cells were much less consistent with that of an affected fetus and conclude that AF supernatant after 14.5 weeks gestation would show abnormally high enzyme activities in an affected I-cell pregnancy. Though, normal AF supernatant results should always be confirmed by studying CAF in pregnancies suspected for ML-II/III [23].

In the present study molecular analysis was carried out in seven cases which include six Tay-Sachs and one Gaucher disease with known mutation and all were in concordance with the enzymes study. It can be affirmed that enzymes study from prenatal fetal tissue is as specific and sensitive as molecular study. Nonetheless mutation detection in the index case is the prerequisite for this.

Although, enzyme based PD for some of the lysosomal disorders often pose a problem of pseudo-deficiencies of few of the lysosomal enzymes [24]. In such cases, mutation analysis as well as enzyme activity is necessary in the parents and the index case before offering PD. The failure to study the presence of a pseudo-deficiency allele in a 
family could lead to an incorrect PD, which is a major limitation of the study. Another confirmative approach is to use biochemical analysis and morphology of $\mathrm{CV}$ tissue, which has been successfully used at Great Ormond Street Hospital for Children in approximately 1,000 pregnancies at risk for LSDs [25].

Selection of the biological material to be used for PD is always a dilemma for clinician due to fetal safety and variable enzymatic activity in different tissues. In most of the studies done so far for PD of LSDs, enzyme activities were measured either from CV, CCV cells, or CAF cells. $\mathrm{CV}$ is the most preferred one owing to benefit of performing direct biochemical analysis with rapid results as compared to cultured amniotic cells that can take days to weeks to provide enough material for biochemical testing. Nevertheless, experience also suggests that the use of CV (uncultured and/or cultured) provides an early result with a safety to the mother's decision while deciding for the termination, in case of an affected pregnancy. The CAF cells can be offered where probability of obtaining material in early pregnancy is less and in cases where CV cells fail to grow in vitro or enzyme activities are poorly expressed where heterozygous and affected status of the fetus is not clear. However, AF is preferred over CV study in pregnancies requiring PD for various MPS disorders and I-cell disease as direct AF study for various enzymes and excretion pattern of chondroitin sulfate, heparan sulfate and dermatan sulfate can be performed as a prenatal screening test. Based on this, confirmative study can be carried out from the cultured cells by carrying out selective lysosomal enzyme investigation.

To conclude, PD of LSDs can be carried out by enzymes study from CV/CCV and CAF with an accuracy of molecular method. However, in cases of MPS and ML-II/ $\mathrm{III}, \mathrm{AF}$ is preferred over $\mathrm{CV} / \mathrm{CCV}$. In addition, special care is needed while interpreting enzyme results encompassing carrier status and need to be further evaluated by molecular study.

Acknowledgments Our sincere thanks to Dr. Mamta Muranjan, Dr. Aparna Kulkarni and Dr. Jigish Trivedi for references. This study was partly supported by ICMR [54/2/2005-BMS] and FRIGE.

Conflict of interest None.

\section{References}

1. Lake B, Young E, Winchester B. Prenatal diagnosis of lysosomal storage diseases. Brain Pathol. 1998;8(1):133-49.

2. Gatti R, Lombardo C, Filocamo M, Borrone C, Porro E. Comparative study of 15 lysosomal enzymes in chorionic villi and cultured amniotic fluid cells. Early prenatal diagnosis in seven pregnancies at risk for lysosomal storage diseases. Prenat Diagn. 1985;5(5):329-36.
3. Whiteman P, Henderson H. A method for the determination of amniotic fluid glycosaminoglycans and its application for prenatal diagnosis of Hurler and Sanfilippo disease. Clin Chim Acta. 1977;79(1):99-105.

4. Ramsay S, Maire I, Bindloss C, Fuller M, Whitfield P, Piraud M, et al. Determination of oligosaccharide and glycolipids in amniotic fluid by electroscopy ionization tandem mass spectrometry: in utero indicator of lysosomal storage disease. Mol Genet Metab. 2004;84(3):231-8.

5. Risch N, Tang H, Katzenstein H, Ekstein J. Geographic distribution of disease mutations in the Ashkenazi Jewish population supports genetic drift over selection. Am J Hum Genet. 2003;72(4):812-22.

6. Kaback M, Lim-Steele J, Dabholkar D, Brown D, Levy N, Zeiger K. Taysach's disease-carrier screening, prenatal diagnosis and the molecular era. An international perspective 1970 to 1993. JAMA. 1993;270(19):2307-15.

7. Natowicz M, Isman F, Prence E, Cedrone P, Allen J. Rapid prenatal testing for human $\beta$-glucuronidase deficiency (MPS VII). Genet Test. 2003;7(3):241-3.

8. Sheth J, Bhattacharya R, Sheth F. Prenatal diagnosis of TaySachs B1 variant in a Maharashtrian family. Indian Pediatr. 2002;39:704-6.

9. Sheth JJ, Sheth FJ, Bhattacharya R. Morquio-B syndrome (MPSIV B) associated with beta-galactosidase deficiency in two siblings. Indian J Pediatr. 2002;69(1):109-11.

10. Verma PK, Ranganath P, Dalal AB, Phadke SR. Spectrum of lysosomal storage disorders at a medical genetics center in northern India. Indian Pediatr. 2012;49(10):799-804 (Epub 30 March 2012).

11. Meikle PJ, Hopwood JJ, Clague AE, et al. Prevalence of lysosomal storage disorders. JAMA. 1999;281(3):249-54.

12. Sheth J, Mistri M, Sheth F, Shah R, Bavdekar A, Godbole K, Nanavaty N, Datar C, Kamate M, Oza N, Ankleshwaria C, Mehta $\mathrm{S}$, Jackson M. Burden of lysosomal storage disorders in India: experience of 387 affected children from a single diagnostic facility. JIMD Rep. 2014; 12:51-63. doi:10.1007/8904_2013_ 244.

13. Sheth J, Patel P, Sheth F, Shah R. Lysosomal storage disorders. Indian Pediatr. 2004;41:260-4.

14. Miller SA, Dykes DD, Polesky HF. A simple salting out procedure for extracting DNA from human nucleated cells. Nucleic Acids Res. 1988;16(3):1215.

15. Trigss-Raine BL, Akerman BR, Clarke JT, Gravel RA. Sequencing of DNA flanking the exons of the HEXA gene, and identification of mutation in Tay-Sachs disease. Am J Hum Genet. 1991;49:1041-54.

16. Mistri M, Tamhankar P, Sheth $\mathrm{F}$, et al. Identification of novel mutations in HEXA gene in children affected with Tay Sachs disease from India. PLoS ONE. 2012;7(6):e39122. doi:10.1371/ journalpone.0039122.

17. Ankleshwaria C, Mistri M, Bavdekar A. Novel mutations in the glucocerebrosidase gene of Indian patients with Gaucher disease. J Hum Genet. 2014;59:223-8. doi:10.1038/jhg.2014.5.

18. Filocamo M, Morrone A. Lysosomal storage disorders: molecular basis and laboratory testing. Hum Genomics. 2011;5(3):156-69.

19. Fukuda M, Tanaka A, Isshiki G. Variation of lysosomal enzyme activity with gestational age in chorionic villi. J Inherit Metab Dis. 1990;13(6):862-6.

20. Young EP. Prenatal diagnosis of Hurler disease by analysis of $\alpha$ iduronidase in chorionic villi. J Inherit Metab Dis. 1992;15(2):224-30.

21. Zhang W, Shi H, Menq Y, Li B, Qiu Z, Liu J. Postnatal and prenatal diagnosis of mucopolysaccharidosis type III. Zhonghu Er Ke Za Zhi. 2008;46(6):407-10.

22. Sanguinetti N, Marsh J, Jackson M, Fensom AH, Warren RC, Rodeck HC. The arylsulphatases of chorionic villi: potential 
problems in the first-trimester diagnosis of metachromatic leucodystrophy and Maroteaux-Lamy disease. Clin Genet. 1986; 30(4):302-8.

23. Besley GT, Broadhead DM, Nevin NC, Nevin J, Dornan JC. Prenatal diagnosis of mucolipidosis II by early amniocentesis. Lancet. 1990;335:1164-5.
24. Thomas GH. "Pseudodeficiencies" of lysosomal hydrolases. Am J Hum Genet. 1994;54(6):934-40.

25. Lake BD. Histopathological investigations of prenatal tissue samples (excluding skin). In: Reed GB, Claireaux AE, Cockburn F, editors. Diseases of the fetus and newborn. 2nd ed. London: Chapman and Hall Medical; 1995. p. 1089-97. 